\title{
Frequency of Various Bleeding Disorders Among Gynecological and Obstetric Patients Presenting with Bleeding
}

\author{
${ }^{1}$ Fauzia Aamer, ${ }^{2}$ Muneeza Natiq, ${ }^{2}$ Sana Khan \\ ${ }^{I}$ Department of Hematology, Services Institute of Medical Sciences, Lahore \\ ${ }^{2}$ Department of Hematology, Allama Iqbal Medical College, Lahore
}

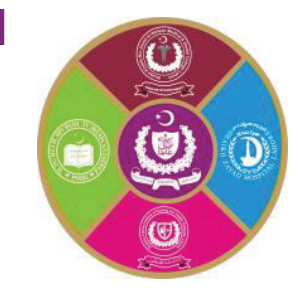

\begin{abstract}
Introduction: Bleeding issues specific to women and adolescent females are common across the world. These issues can present either due to gynecological causes or obstetric one; however these can result in significant morbidity and work up needs to be done to rule out any underlying bleeding diathesis. Aims \& Objectives: To determine frequency of various bleeding disorders among gynecological and obstetric patients presenting with bleeding. Place and duration of study: It is a cross sectional study which was conducted in the Hematology Department, Services Institute of Medical Sciences, Lahore. The duration of study was 6 months i.e from $21^{\text {st }}$ Oct, 2018 to $30^{\text {th }}$ April, 2019. Material \& Methods: Females with age range of 15 to 50 years irrespective of pregnancy presenting as menorrhagia, metrorrhagia or obstetrical bleeding were included. Results: In the present study there were total 140 cases with mean age of $30.14 \pm 9.59$ years. There were $98(70 \%)$ cases that were pregnant. There were $35(25 \%)$ cases presented with PPH (Post Partum Hemorrhage), 42 (30\%) with IPH (Intra Partum Hemorrhage), 49 (35\%) with menorrhagia and 14 (10\%) with metrorrhagia. HELLP (Hemolysis, Elevated Liver enzymes and Low Platelet count) syndrome was seen in 13 $(9.29 \%)$ cases, DIC (Disseminated Intravascular Coagulation) in $2(1.43 \%)$, gestational thrombocytopenia in $7(5 \%)$, while factor deficiency in $34(24.29 \%)$ cases; and $84(60 \%)$ of cases revealed none of the bleeding disorder. Out of total 34 cases of factor deficiencies, vWD was the most common, seen in $20(58.82 \%)$ cases. There was none of the cases seen having deficiency of factor II, VII, VIII, XI, XII. HELLP syndrome was seen in $11(84.62 \%)$ of the cases with age group 15 to 32 years and similarly both cases of DIC were seen in same age group; but the difference in both the age groups regarding these bleeding disorders was not statistically significant with $p=0.38$. There was no significant difference in terms of pregnancy; however, both cases of DIC were seen in pregnancy with insignificant $\mathrm{p}$ value of 0.51 . HELLP syndrome was more seen in IPH affecting 5 (38.40\%), factor deficiency in menorrhagia affecting $13(38.2 \%)$ with $p$ value of 0.61 . vWD and factor V Leiden presented in $44.4 \%$ cases each with PPH, and vWD affected $87.5 \%$ of cases in IPH without any significant difference with $\mathrm{p}=0.42$. Conclusion: Bleeding disorders are not uncommon in gynecological and obstetric conditions. Factor deficiency were the most common causes and amongst these vWD was the most deficient factor. There was no significant association with any confounding variable; however, DIC was only seen in obstetrical conditions.
\end{abstract}

Key words: Bleeding, menorrhagia, HELLP, DIC, IPH, PPH

\section{INTRODUCTION}

$\mathrm{B}_{1}$ leeding issues specific to women and adolescent females are common across the world. These issues relate particular to menses, pregnancy and childbirth. Women with bleeding disorders can have symptoms that result in significant morbidity and impact their quality of life. ${ }^{1-2}$ Menorrhagia and metrorrhagia are important issues reflecting excessive bleeding at the time of menstruation and irregular in between respectively and often reflect the underlying bleeding disorders in females. According to a study it affects as many as $10-50 \%$ of women. ${ }^{3}$ Others gynecological complications of bleeding disorders are hemorrhagic ovarian cyst, endometrial hyperplasia and endometriosis. While in pregnancies intra and post-partum hemorrhage are important presentations and pose a lot of stress in the acute emergency conditions. Other important obstetrical conditions leading to bleeding disorders are DIC, HELLP syndrome and gestational 
thrombocytopenia..$^{4-5}$ Bleeding disorders can be inherited and acquired. Inherited bleeding disorders are not so infrequent and can increase frequency and severity of bleeding complications during and after pregnancy. ${ }^{4}$ Studies have shown that Von willebrand disease is the commonest inherited bleeding disorder in gynecological patients with menorrhagia, consistently reported to be $10 \%$ to $20 \%{ }^{4}$ According to another study by Janbabai $G$ et al deficiencies of different factors were seen as factor II, V, VII, VIII, IX, X , XI, XII, XIII in 0.73, 1.0, 1.80, 1.50, 0.37, $0.37,1.80,2.20$ and $0 \%$ respectively. ${ }^{6}$ A study by Ashraf $\mathrm{M}$ et al revealed HELLP syndrome in $28 \%$, gestational thrombocytopenia in $22 \%$, von Willibrand disease in $16.66 \%$ and factor $\mathrm{V}$ deficiency in $6 \%$ of cases. ${ }^{7}$ The data regarding the causes and frequencies of different bleeding disorders is variable ${ }^{6-7}$ and factor deficiencies is an under reported cause of bleeding specially in pregnant females. Therefore this study was planned, to determine the frequency of bleeding disorders in such patients and help to develop some practical recommendations for routine practice guidelines. This would enable early diagnosis and management and reduce the morbidity and mortality rate.

\section{MATERIAL AND METHODS}

It is a cross sectional study which was performed in the Department of Hematology, Services Institute of Medical Sciences, Lahore. Duration of study was 6 months from $21^{\text {st }}$ Oct, 2018 to $30^{\text {th }}$ April, 2019. The sample size was calculated as 140 by non-probable and consecutive method, keeping in view the confidence level equal to $95 \%$ and the margin of error equal to $4 \%$ and $p$ (the prevalence of factor deficiency) as $6 \%$..

\section{Inclusion criteria:}

1. Female patients with age between 15-50 years.

2. All obstetric/gynae patients with bleeding manifestations like intra and postpartum haemorrhage, menorrhagia and metrorrhagia as per operational definition.

\section{Exclusion criteria:}

1. All patients taking warfarin, aspirin, clopidogril or on heparin within last 2 weeks.

2. Women using oral contraceptive pills on their previous menstrual cycles

3. Patients having IUD (Intrauterine device).

Data Collection Procedure: After permission from the Ethical Review Committee, total number of 140 patients fulfilling the inclusion and exclusion criteria were selected. After taking informed written consent, relevant history was taken from patients regarding pregnancy and bleeding. Every patient underwent complete blood count (by Sysmex KX21), Prothrombin time and activated Prothrombin time (performed manually using water bath and reagent) and ALT. Amongst the cases that did not have pregnancy and had platelet count less than $100,000 \mu 1$ were noted as thrombocytopenia and the cases that had normal platelet but raised level of PT or APTT were checked directly for clotting factor assay as per operational definition by STAGO kit and the result were noted. Those cases that had pregnancy and had platelet count less than $100,000 \mu \mathrm{l}$; were again assessed for ALT, fibrinogen level and FDP level. They were then labeled as gestational thrombocytopenia, DIC, or HELLP syndrome as per operational definitions. Those cases with all these normal studies underwent factor assay and were labelled for any factor deficiency as per operational definition and Von Wilibrand disease was labelled when Vwf; RCO was $<30$ iu $/ \mathrm{dl}$ and Vwf; ag $<30-50 \mathrm{iu} / \mathrm{dl}$. The results were noted on a specially designed proforma.

\section{Statistical analysis:}

Statistical analysis was performed using SPSS version 20. Results were presented as mean and standard deviation for quantitative variables i.e. age, frequency and percentage were calculated for qualitative variable like pregnant or not, thrombocytopenia, HELLP syndrome, DIC, gestational thrombocytopenia, factor deficiency and type of factor deficiency. Effect modifiers were controlled through stratification of age, pregnancy, type of bleeding. Post stratification Chi Square test was applied and $p$ value $\leq 0.05$ was considered as significant.

\section{RESULTS}

In the present study there were total 140 cases with mean age of $30.14 \pm 9.59$ years with minimum age of 15 years and maximum 49 years as shown in table 01 . There were $98(70 \%)$ cases that were pregnant as in fig- 1 . There were $35(25 \%)$ cases presented with $\mathrm{PPH}, 42(30 \%)$ with IPH, 49 (35\%) with menorrhagia and $14(10 \%)$ with metrorrhagia (Fig2). Thrombocytopenia was detected in $20(14.29 \%)$ of cases out of which 13 were cases of HELLP and 7 in gestational thrombocytopenia (Fig-3). HELLP syndrome was seen in $13(9.29 \%)$ cases, DIC in 2 $(1.43 \%)$, gestational thrombocytopenia in $7(5 \%)$, while factor deficiency in $34(24.29 \%)$ cases; and 84 $(60 \%)$ of cases revealed none of the bleeding disorder (Fig-4). Out of total 34 cases of factor deficiencies, vWD (Vwf; RCO $<30 \mathrm{iu} / \mathrm{dl}$ and Vwf; ag $<30-50 \mathrm{iu} / \mathrm{dl}$ ) was the most common seen in 20 
$(58.82 \%)$ of cases followed by Factor V Leiden seen in $11(32.35 \%)$ of cases as in fig-5. There was none of the cases seen having deficiency of factor II, VII, VIII, XI, XII. HELLP syndrome was seen in 11 $(84.62 \%)$ of the cases with age group 15 to 32 years and similarly both cases of DIC were seen in same age group; but the difference in both the age groups regarding these bleeding disorders was not statistically significant with $\mathrm{p}=0.38$ as shown in Table-2. There was no significant difference in terms of pregnancy; however, both cases of DIC were seen in pregnancy as well with insignificant $p$ value of 0.51 as in Table-3. HELLP syndrome was more seen in IPH affecting $5(38.40 \%)$, factor deficiency in menorrhagia affecting $13(38.2 \%)$ with $\mathrm{p}$ value of 0.61 (table 04 ). $\mathrm{vWD}$ and factor V Leiden presented in $44.4 \%$ cases each with $\mathrm{PPH}$, and vWD affected $87.5 \%$ of cases in IPH without any significant difference with $\mathrm{p}=0.42$ (Table-5)

\begin{tabular}{|c|l|c|}
\cline { 2 - 2 } \multicolumn{2}{c|}{} & Age \\
\hline \multicolumn{2}{|c|}{ Mean } & 30.14 \\
\hline $\begin{array}{l}\text { 95\% Confidence } \\
\text { Interval for Mean }\end{array}$ & Lower Bound & 28.54 \\
\cline { 2 - 3 } & Upper Bound & 31.75 \\
\hline \multicolumn{2}{|c|}{ Median } & 26.50 \\
\hline \multicolumn{2}{|c|}{ Std. Deviation } & 9.59 \\
\hline \multicolumn{2}{|c|}{ Minimum } & 15 \\
\hline \multicolumn{2}{|c|}{ Maximum } & 49 \\
\hline
\end{tabular}

Table-1: Study Variables (Age)

$\mathrm{n}=140$

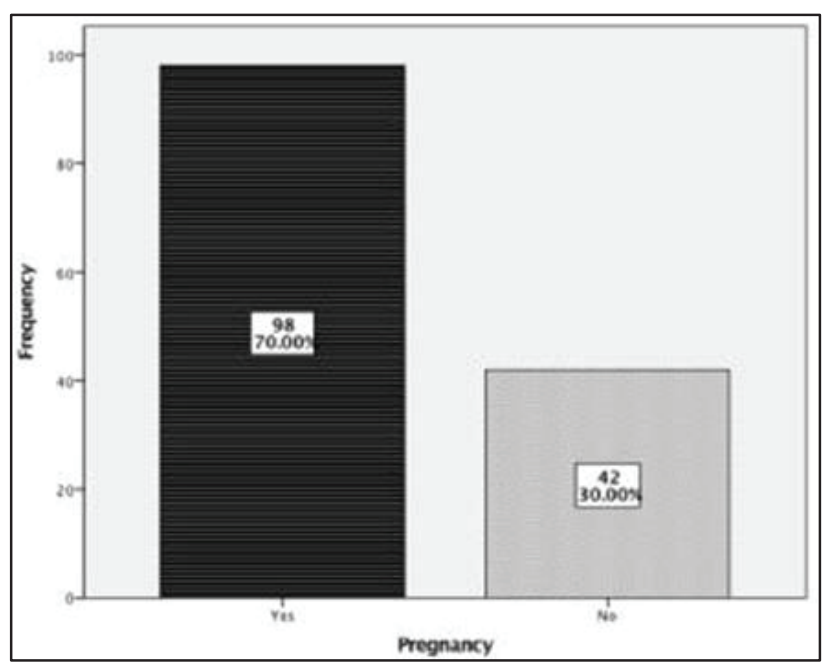

Fig-1: Pregnancy in study subjects

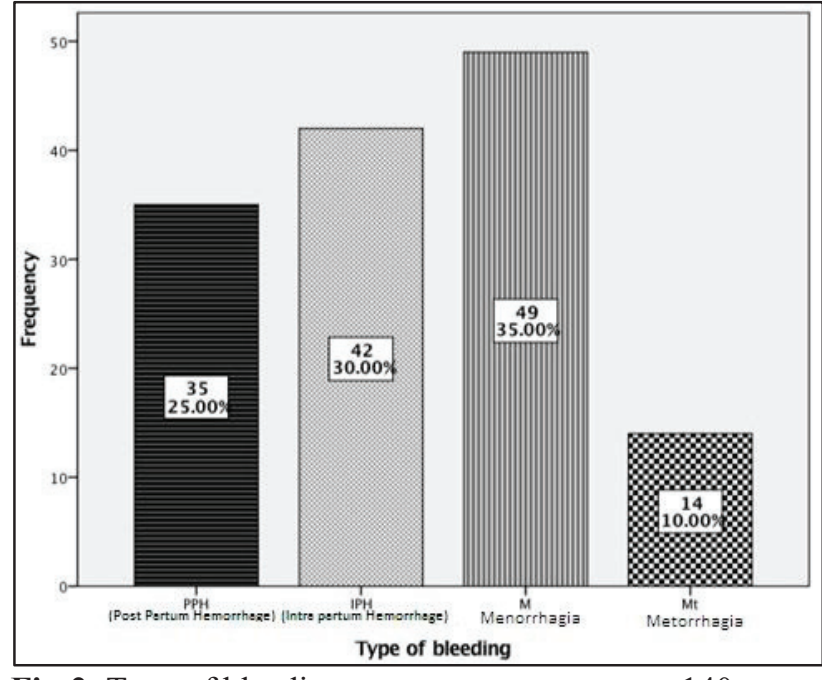

Fig-2: Type of bleeding

$\mathrm{n}=140$

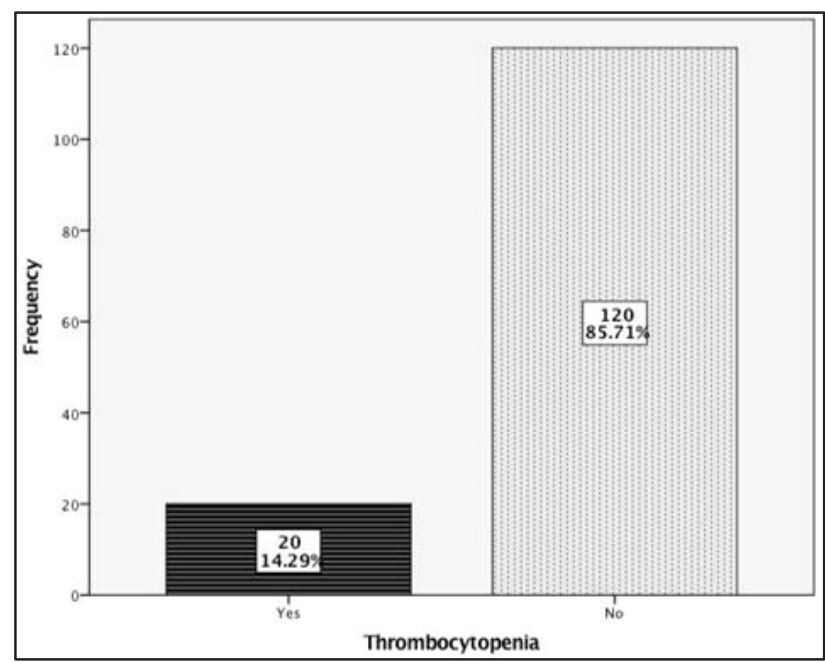

Fig-3: Thrombocytopenia detected $n=140$

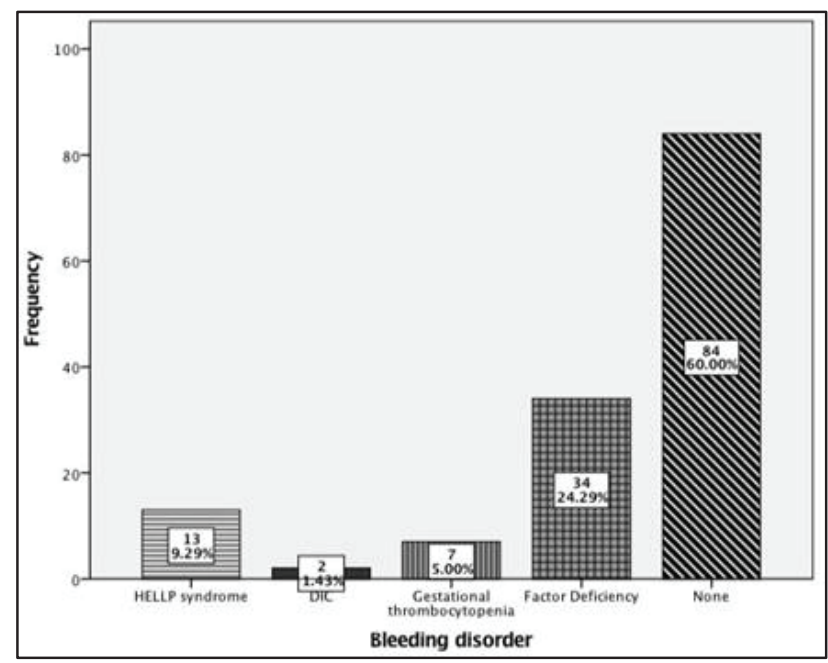

Fig-4: Type of bleeding disorder detected $n=140$ 


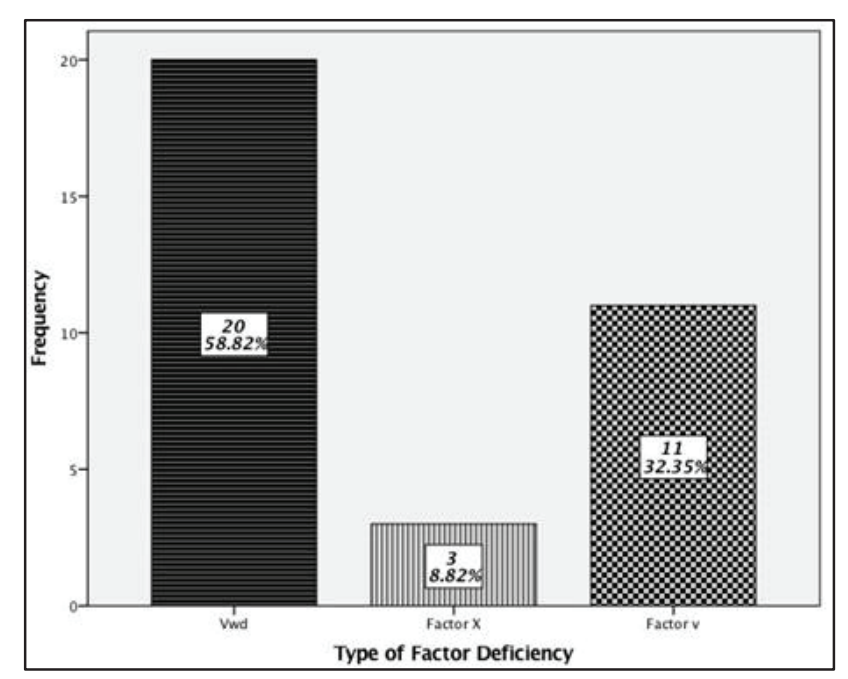

Fig-5: Type of factor deficiency

$n=140$

\begin{tabular}{|c|c|c|c|}
\hline \multirow{2}{*}{$\begin{array}{c}\text { Bleeding } \\
\text { Disorder }\end{array}$} & \multicolumn{2}{|c|}{ Age Groups } & \multirow{2}{*}{ Total } \\
\cline { 2 - 3 } & $\mathbf{1 5 - 3 2}$ & $\mathbf{3 3 - 5 0}$ & \\
\hline $\begin{array}{c}\text { HELLP } \\
\text { syndrome }\end{array}$ & $\begin{array}{c}11 \\
(84.62 \%)\end{array}$ & $\begin{array}{c}02 \\
(15.38 \%)\end{array}$ & $\begin{array}{c}13 \\
(100 \%)\end{array}$ \\
\hline DIC & $\begin{array}{c}02 \\
(100 \%)\end{array}$ & $\begin{array}{c}00 \\
(00 \%)\end{array}$ & $\begin{array}{c}02 \\
(100 \%)\end{array}$ \\
\hline $\begin{array}{c}\text { Gestational } \\
\text { thrombocytopenia }\end{array}$ & $\begin{array}{c}05 \\
(71.43 \%)\end{array}$ & $\begin{array}{c}02 \\
(28.57 \%)\end{array}$ & $\begin{array}{c}07 \\
(100 \%)\end{array}$ \\
\hline Factor deficiency & $\begin{array}{c}21 \\
(61.76 \%)\end{array}$ & $\begin{array}{c}13 \\
(38.24 \%)\end{array}$ & $\begin{array}{c}34 \\
(100 \%)\end{array}$ \\
\hline None & $\begin{array}{c}51 \\
(60.71 \%)\end{array}$ & $\begin{array}{c}33 \\
(39.29 \%)\end{array}$ & $\begin{array}{c}84 \\
(100 \%)\end{array}$ \\
\hline Total & $\begin{array}{c}90 \\
(64.28 \%)\end{array}$ & $\begin{array}{c}50 \\
(35.72 \%)\end{array}$ & $\begin{array}{c}140 \\
(100 \%)\end{array}$ \\
\hline
\end{tabular}

$\mathrm{n}=140, \mathrm{p}=0.38$

Table-2: Bleeding disorder with respect to age groups

\begin{tabular}{|c|c|c|c|}
\hline \multirow{2}{*}{$\begin{array}{l}\text { Bleeding } \\
\text { Disorder }\end{array}$} & \multicolumn{2}{|c|}{ Pregnancy } & \multirow{2}{*}{ Total } \\
\hline & Yes & No & \\
\hline $\begin{array}{c}\text { HELLP } \\
\text { syndrome }\end{array}$ & $\begin{array}{c}8 \\
(61.53 \%) \\
\end{array}$ & $\begin{array}{c}5 \\
(38.47 \%) \\
\end{array}$ & $\begin{array}{c}13 \\
(100 \%) \\
\end{array}$ \\
\hline DIC & $\begin{array}{c}02 \\
(100 \%)\end{array}$ & $00(00 \%)$ & $\begin{array}{c}02 \\
(100 \%)\end{array}$ \\
\hline $\begin{array}{c}\text { Gestational } \\
\text { thrombocytopenia }\end{array}$ & $\begin{array}{c}7 \\
(100 \%)\end{array}$ & $\begin{array}{c}0 \\
(0 \%)\end{array}$ & $\begin{array}{c}07 \\
(100 \%)\end{array}$ \\
\hline Factor deficiency & $\begin{array}{c}26 \\
(76.47 \%)\end{array}$ & $\begin{array}{c}8 \\
(23.53 \%)\end{array}$ & $\begin{array}{c}34 \\
(100 \%)\end{array}$ \\
\hline None & $\begin{array}{c}55 \\
(66.67 \%)\end{array}$ & $\begin{array}{c}29 \\
(33.33 \%)\end{array}$ & $\begin{array}{c}84 \\
(100 \%)\end{array}$ \\
\hline Total & $\begin{array}{c}98 \\
(70 \%)\end{array}$ & $\begin{array}{c}42 \\
(30 \%)\end{array}$ & $\begin{array}{c}140 \\
(100 \%)\end{array}$ \\
\hline
\end{tabular}

$\mathrm{n}=140, \mathrm{p}=0.51$

Table-3: Bleeding disorder with respect to pregnancy

\begin{tabular}{|c|c|c|c|c|c|}
\hline \multirow{2}{*}{$\begin{array}{l}\text { Bleeding } \\
\text { Disorder }\end{array}$} & \multicolumn{4}{|c|}{ Type of Bleeding } & \multirow{2}{*}{ Total } \\
\hline & PPH & IPH & M & Mt & \\
\hline $\begin{array}{l}\text { HELLP } \\
\text { syndrome }\end{array}$ & $\begin{array}{c}2 \\
(15.3 \%\end{array}$ & $\begin{array}{c}5 \\
(38.46 \%\end{array}$ & $\begin{array}{c}4 \\
(30.7 \%\end{array}$ & $\begin{array}{c}2 \\
(15.3 \%)\end{array}$ & $\begin{array}{c}13 \\
(100 \%)\end{array}$ \\
\hline DIC & $\begin{array}{c}2 \\
(100 \%)\end{array}$ & $\begin{array}{c}0 \\
(0 \%)\end{array}$ & $\begin{array}{c}0 \\
(0 \%)\end{array}$ & $\begin{array}{c}0 \\
(0 \%)\end{array}$ & $\begin{array}{c}02 \\
(100 \%)\end{array}$ \\
\hline $\begin{array}{c}\text { Gestational } \\
\text { hrombocytopenia }\end{array}$ & $\begin{array}{c}0 \\
(0 \%)\end{array}$ & $\begin{array}{c}1 \\
(14.3 \%)\end{array}$ & $\begin{array}{c}4 \\
(57.1 \%\end{array}$ & $\begin{array}{c}2 \\
(28.6 \%)\end{array}$ & $\begin{array}{c}07 \\
(100 \%)\end{array}$ \\
\hline $\begin{array}{c}\text { Factor } \\
\text { deficiency }\end{array}$ & $\begin{array}{c}9 \\
(26.5 \%\end{array}$ & $\begin{array}{c}8 \\
(23.5 \%)\end{array}$ & $\begin{array}{c}13 \\
(38.2 \%\end{array}$ & $\begin{array}{c}4 \\
(11.8 \%)\end{array}$ & $\begin{array}{c}34 \\
(100 \%)\end{array}$ \\
\hline None & $\begin{array}{c}22 \\
(26.2 \%\end{array}$ & $\begin{array}{c}28 \\
(33.3 \%)\end{array}$ & $\begin{array}{c}28 \\
(33.3 \%\end{array}$ & $\begin{array}{c}6 \\
(7.14 \%)\end{array}$ & $\begin{array}{c}84 \\
(100 \%)\end{array}$ \\
\hline Total & $\begin{array}{c}35 \\
(25 \%)\end{array}$ & $\begin{array}{c}42 \\
(30 \%)\end{array}$ & $\begin{array}{c}49 \\
(35 \%)\end{array}$ & $\begin{array}{c}14 \\
(10 \%)\end{array}$ & $\begin{array}{c}140 \\
(100 \%)\end{array}$ \\
\hline
\end{tabular}

$\mathrm{n}=140, \mathrm{p}=0.61$

Table-4: Bleeding disorder with respect to type of bleeding

\begin{tabular}{|c|c|c|c|c|}
\hline \multirow{2}{*}{$\begin{array}{c}\text { Types of } \\
\text { Bleeding }\end{array}$} & \multicolumn{2}{|c|}{ Type of Factor Deficiency } & \multirow{2}{*}{ Total } \\
\cline { 2 - 5 } & vWD & Fact X & Factor V & \\
\hline PPH & 4 & 1 & 4 & 9 \\
& $(44.4 \%)$ & $(11.2 \%)$ & $(44.4 \%)$ & $(100 \%)$ \\
\hline \multirow{2}{*}{ IPH } & 7 & 0 & 1 & 8 \\
& $(87.5 \%)$ & $(0 \%)$ & $(12.5 \%)$ & $(100 \%)$ \\
\hline \multirow{2}{*}{ M } & 8 & 1 & 4 & 13 \\
& $(61.5 \%)$ & $(7.6 \%)$ & $(30.8 \%)$ & $(100 \%)$ \\
\hline \multirow{2}{*}{ Mt } & 1 & 1 & 2 & 4 \\
& $(25 \%)$ & $(25 \%)$ & $(50 \%)$ & $(100 \%)$ \\
\hline \multirow{2}{*}{ Total } & $\mathbf{2 0}$ & $\mathbf{3}$ & $\mathbf{1 1}$ & $\mathbf{3 4}$ \\
& $(\mathbf{1 1 . 8 \% )}$ & $\mathbf{( 8 . 8 2 \% )}$ & $\mathbf{( 3 2 . 4 \% )}$ & $\mathbf{( 1 0 0 \% )}$ \\
\hline
\end{tabular}

$\mathrm{n}=34, \quad \mathrm{p}=0.42$

Table-5: Type of bleeding with respect to type of factor deficiency

\section{DISCUSSION}

Bleeding disorders can be inherited and acquired. Inherited disorders improve during pregnancy while acquired disorders tend to worsen and bleeding problems unique to pregnancy may occur. Similarly, incidence of bleeding disorders is higher in patients with menorrhagia than in general population. ${ }^{8}$ In developing countries like ours majority of bleeding disorders remain undiagnosed until the patient presents with massive haemorrhage or undergoes some surgery. The purpose of this study was to evaluate the frequency and type of bleeding disorders in gynaecological and obstetrical practice in Pakistan and also to determine the common presenting symptoms.

There were 35 (25\%) cases presented with PPH, 42 (30\%) with IPH, 49 (35\%) with menorrhagia and 14 $(10 \%)$ with metrorrhagia in the present study. This finding was similar to the studies done in previous settings. According to a study done by Trasi SA et al, they also found that menorrhagia was the most 
commonly observed bleeding subtype that presented for the workup of bleeding disorders and it was seen in $25-30 \%$ of the cases. ${ }^{8}$ According to this study, it was observed that this was the major factor and due to excessive bleeding, risk of anemia and fear of any complications were the major concerns that led to the workup of any bleeding disorders as compared to the other entities. These findings of menorrhagia in highest number leading to diagnostic workup was also seen by James at al in their study in $2010 .{ }^{9}$

In the present study HELLP syndrome was seen in $13(9.29 \%)$ cases, DIC in $2(1.43 \%)$, gestational thrombocytopenia in $7(5 \%)$, while factor deficiency in $34(24.29 \%)$ cases; and $84(60 \%)$ of cases revealed none of the bleeding disorder. Out of total 34 cases of factor deficiencies, factor VIII was the most common seen in $16(47.06 \%)$ of cases followed by Factor V Leiden seen in 11 (32.35\%) of cases. These findings were close to the studied done in the past. According to a study done by Ashraf M et al on 3523 cases, the bleeding disorders were seen in eighteen patients $(0.5 \%)$ cases. $^{10}$ The types of bleeding disorders in decreasing order of frequency were HELLP syndrome $(27.7 \%, n=5)$, gestational thrombocytopenia $(22 \%, \mathrm{n}=4)$, Von Willebrand disease $(16.66 \%, \mathrm{n}=3)$, Glanzmann's thrombesthenia $(11.11 \%, \mathrm{n}=2)$, autoimmune haemolytic anaemia $(11.11 \%, n=2)$, post-transfusion purpura $(6 \%, n=1)$ and factor $\mathrm{V}$ deficiency $(6 \%, \mathrm{n}=1)$.

Gestational thrombocytopenia was the second most common bleeding disorder in this study and was seen in $24 \%(24.29 \%)$ of cases. This finding was also similar to the studies done in Pakistan where it was seen in $22 \%$ of the cases ${ }^{10}$. However, in the data from the other survey, the reported incidence of this condition is $8 \%$ of all pregnancies ${ }^{11}$. This difference in the frequency of this disorder can be due to the difference in the operational definitions. Because the results were similar from study of Ashraf et al where they also used the same cut off value where they only evaluated those patients who had thrombocytopenia less than 100,000/ul.

vWD was the most common factor deficiency was seen and was noted in $20(58.82 \%)$ of the cases, followed by Factor V Leiden seen in $11(32.35 \%)$ and factor $\mathrm{X}$ deficiency seen in $3(8.82 \%)$ out of 34 cases with factor deficiencies in this study. Similar result was seen in other studies, where Von Willbrand disease was the most common bleeding disorder in terms of factor deficiency with a frequency of $0.2 \%$. In another study this was reported to have incidence of $0.8-1.3 \%{ }^{12}$. In terms of frequency vWD disease was seen in $14.28 \%$ of the cases which was slightly high as compared to the previous studies. In a study by Shankar et al vWD was seen in $5.9 \%$ of the cases ${ }^{13}$.

According to a study done in Iran they found factor $\mathrm{V}$ Leiden as the most among eh factor deficits and it was seen in $8 \%$ of the cases while vWD was seen in $5.9 \%$ of the cases ${ }^{14}$. In another study by Anne Dilley they also found vWD as the most common causes and they found in in $6.6 \%$ of the cases ${ }^{15}$. Interestingly they found factor deficiencies in the least number of cases where the overall incidence was seen in only $1.6 \%$ of the cases. Whereas conflicting results were observed in the present study and since it was the most common cause, seen in $34(24.29 \%)$ of the cases. This marked difference of incidence of high number of cases diagnosed with bleeding disorders presenting with heavy bleeding can be explained by the fact that people usually don't seek medical attentions at earlier stages as compared to the developed countries and only those cases were reported which are highly morbid and suffer such illness again and again

This was also supported by the study of Saxena et al, where they only studied the cases presented with menorrhagia and it was seen that bleeding disorder was seen in as high as $15.3 \%$ of the cases. ${ }^{16}$ This also supports our study as we conducted the four parameters and amongst them the incidence rate to find such illness was high. The above mentioned statement can be further strengthened by this Indian study as they also have same health care system as in Pakistan with similar poverty rates as well. The study from Trasi et al also revealed the incidence of bleeding disorder in $19.16 \%$ of the cases. ${ }^{8}$

Gestational thrombocytopenia was seen in $7(5 \%)$ cases in the present study. The results were similar to the studies done by Philipp et al. ${ }^{17}$ There was no significant difference in terms of age groups for the involvement of the any particular bleeding disorder. According to a study done by Janbabai $\mathrm{G}$ et al, they also did not find any significant difference in different age group; however, they used slight different groups than our study and used the cut off value of less than 20 and 20 to 40 years of age. ${ }^{14}$ The data was lacking in terms of confounding factor of pregnancy and which affected the both cases of disseminated intravascular coagulation and none of the gynaecological case suffered this. This explains the complex pathophysiological changes that can lead to development of DIC. And both of these cases presented with post partumhaemorrhage.

There were few limitations of these studies as this study did not compare this workup with a control group. Secondly this study also did not collect the data regarding the duration of illness for which these cases were suffering this disorder. 
However, there were many strengthening points as well as this study comprehensively discussed a wide range of not only inclusion criteria; but also the variety of the bleeding disorders; also studied such cases irrespective of pregnancy.

\section{CONCLUSION}

Bleeding disorders are not uncommon in gynecological and obstetric conditions. Factor deficiency was the most common causes and amongst these vWD was the most deficient factor. There was no significant association with any confounding variable; however, DIC was only seen in obstetrical conditions.

\section{REFERENCES}

1. Lefkou E, Hunt BJ. Bleeding disorders in pregnancy. Obstet Gynaecol Reprod Med. 2008; 18:213-18.

2. Philipp CS, Faiz A, Dowling N, Dilley A, Michaels LA, Ayers C, et al. Age and prevalence of bleeding disorders in woman with menorrhagia. Obstet Gynaecol. 2005; 105:61-6.

3. Trasi SA, Pathare SD, Shetty K, Ghosh V, Salvi D. The spectrum of bleeding disorders in women with menorrhagia: a report from Western India. Ann. Hematol. 2005;84:339-342

4. Gringeri A, Mangiagali I, Elina R. Congenital bleeding disorders and pregnancy. Haematoligca reports. 2009; 1(10):43-46.

5. James AH. Haemophilia. 2010; 16(5):160-167

6. Ashraf M, Sher Z, Irum N. Bleeding disorders in obstetrics and gyanecological practice. J Coll Phys Surg Pak. 2012; 22(3):192-93.

7. Janbabai G, Borhani SS, Ahmadinejad M. Frequency of bleeding disorders in women presenting with menorrhagia in North of Iran. World ApplSci J. 2013; 23(1): 01-06.

8. Trasi SA, Pathare AV, Shetty SD, Ghosh K, Salvi V and Mohanty D. The spectrum of bleeding disorders in women with menorrhagia: a report from Western India. Ann. Hematol. 2005; 84: 339-342.

9. James AH, Ragni MV and Picozzi VJ. Bleeding disorders in premenopausal women: (another) public health crisis for hematology? Hematol. Am. Soc. Hematol. Educ. Program 2006; pp: 474-485.

10. Ashraf M, Sher Z, Irum N. Bleeding disorders in obstetrics and gyanecological practice. J Coll Phys Surg Pak. 2012; 22(3):192-93.

11. Kramer W, Weiner C. Disorders of haemostasis. In: Cohen WR, Merkatz IR, editors. Cherry and Merkatz's complications of pregnancy. 5th ed. Philadelphia: Lippincott, Williams \& Wilkins; 2000. p. 367-90.

12. Werner EJ, Broxson EH, Tucker EL, Giroux DS, Shults J, Abshire TC. Prevalence of von Willebrand disease in children: a multiethnic study. J Pediatr. 1993; 123:893-8.

13. Shankar M, Lee CA, Sabin CA, Economides DL and Kadir RA. von Willebrand disease in women with menorrhagia: a systematic review. BJOG. 2004; 111: 734-740.

14. Janbabai G, Borhani SS, Ahmadinejad M. Frequency of bleeding disorders in women presenting with menorrhagia in North of Iran. World ApplSci J. 2013; 23(1): 01-06.

15. Dilley A, Drews C, Miller C, Lally C, Austin H, Ramaswamy D, Lurye D and Evatt B. von Willebrand disease and other inherited bleeding disorders in women with diagnosed menorrhagia. Obstet. Gynecol. 2001;97:630-36

16. Saxena R, Gupta M, Gupta PK, Kashyap R, Choudhry VP and Bhargava $M$. Inherited bleeding disorders in Indian women with menorrhagia. Haemoph. 2003; 9:193-196.

17. Philipp CS, Faiz A, Dowling N, Dilley A, Michaels LA, Ayers C, Miller CH, Bachmann G, Evatt B and Saidi P. Age and the prevalence of bleeding disorders in women with menorrhagia. Obstet. Gynecol. 2005; 105:61-66

\section{The Authors:}

Dr. Fauzia Aamer

Assistant Professor, Department of Hematology,

Services Institute of Medical Sciences, Lahore

Dr. Muneeza Natiq

Associate Professor,

Department of Haematology,

Allama Iqbal Medical College, Lahore.

Dr. Sana Khan

P.G. Resident,

Department of Hematology,

Allama Iqbal Medical College, Lahore.

\section{Corresponding Author:}

Dr. Fauzia Aamer

Assistant Professor, Department of Hematology, Services Institute of Medical Sciences, Lahore E-mail: drfauzia.haem@gmail.com 